\title{
Fluorescent and electrochemical dual-mode detection of Chikungunya virus E1 protein using fluorophore-embedded and redox probe-encapsulated liposomes
}

\author{
Fahmida Nasrin ${ }^{1}$ - Ankan Dutta Chowdhury ${ }^{2}$ - Akhilesh Babu Ganganboina ${ }^{2} \cdot$ Ojodomo J. Achadu ${ }^{2}$. \\ Farzana Hossain ${ }^{1}$. Masahito Yamazaki ${ }^{3}$ Enoch Y. Park ${ }^{1,2}$ (D)
}

Received: 25 August 2020 / Accepted: 18 November 2020 / Published online: 25 November 2020

(C) Springer-Verlag GmbH Austria, part of Springer Nature 2020

\begin{abstract}
The critical goal of sensitive virus detection should apply in the early stage of infection, which may increase the probable survival rate. To achieve the low detection limit for the early stage where a small number of viruses are present in the sample, proper amplified signals from a sensor can make readable and reliable detection. In this work, a new model of fluorescent and electrochemical dual-mode detection system has been developed to detect virus, taking recombinant Chikungunya virus E1 protein (CHIK-VP) as an example. The hydrophobic quantum dots (QDs) embedded in the lipid bilayer of liposome and methylene blue (MB) encapsulated in the inner core of liposomes played a role of dual-signaling modulator. After CHIK-VP addition, the nanocomposites and APTES-coated $\mathrm{Fe}_{3} \mathrm{O}_{4}$ nanoparticles $\left(\mathrm{Fe}_{3} \mathrm{O}_{4} \mathrm{NPs}\right)$ were conjugated with antibodies to form a sandwich structure and separated from the medium magnetically. The nanoconjugates have been burst out by chloroform as surfactant, and both the QDs and MB are released from the liposome and were then monitored through changes in the fluorescence and electrochemical signals, respectively. These two fluorometric and electrochemical signals alteration quantified the CHIK-VP in the range of femtogram to nanogram per milliliter level with a LOD of $32 \mathrm{fg} \mathrm{mL}^{-1}$, making this liposomal system a potential matrix in a virus detection platform.
\end{abstract}

Keywords Liposomes Q Quantum dots - Biosensor - Chikungunya virus protein . Fluorescence detection . Electrochemical detection

\section{Introduction}

Virus detection with higher sensitivity and selectivity, along with the presence of other interferences, is of great importance

Fahmida Nasrin and Ankan Dutta Chowdhury contributed equally to this work.

Enoch Y. Park

park.enoch@shizuoka.ac.jp

Fahmida Nasrin

fahmida.nasrin.17@shizuoka.ac.jp

Ankan Dutta Chowdhury

ankan.dutta.chowdhury@shizuoka.ac.jp

Akhilesh Babu Ganganboina

akhilesh.babu.ganganboina@shizuoka.ac.jp

Ojodomo J. Achadu

ojodomo.john.achadu@shizuoka.ac.jp

Farzana Hossain

farzana.hossain.17@shizuoka.ac.jp to control the annual epidemic [1-5]. In most viral diseases, the progress of vaccination is a time-consuming process that encourages the necessity for the development of rapid sensing technologies to prevent the viral outbreak. The rapid yamazaki.masahito@shizuoka.ac.jp

1 Laboratory of Biotechnology, Graduate School of Science and Technology, Shizuoka University, 836 Ohya, Suruga-ku, Shizuoka 422-8529, Japan

2 Laboratory of Biotechnology, Research Institute of Green Science and Technology, Shizuoka University, 836 Ohya, Suruga-ku, Shizuoka 422-8529, Japan

3 Research Institute of Electronics, Shizuoka University, 836 Ohya, Suruga-ku, Shizuoka 422-8529, Japan 
identification and quantification of viruses in all possible samples are of great significance for prompt treatment and effective management of illness [6-8]. Conventional virus detection methods like polymerase chain reaction (PCR) and other branched-chain DNA-based methodologies are not well suited for point-of-care diagnosis $[9,10]$. These are time-consuming and expensive and require intensive sample preparation with high skilled personnel [11-13]. Therefore, the development of an alternative method of virus detection is in high demand, detecting the viruses in its early stage of infection with high sensitivity and performing real-time monitoring purposes.

Target amplification is employed using the liposomal matrix to attain high sensitivity, which has emerged in the last decade as an attractive approach where a target virus bound to a single liposome can generate amplified signals by releasing the encapsulated signal probes [14-17]. Therefore, a small number of viruses can generate an intense signal from the liposome's encapsulated probes [18-21]. Moreover, the encapsulated signal probes can be protected inside the liposome until the external triggers appear and significantly reduce the background noise, which is the great advantage of using liposome-based systems. However, in a real-time application, to attain the detectability of the virus at a very low concentration in the sample medium where a lot of impurities can interfere with the sensing, it is essential to purify the target virus from its medium. To achieve this, the well-established $\mathrm{Fe}_{3} \mathrm{O}_{4}$ magnetic nanoparticles can be extremely useful for removing the interferences from the virus-loaded liposomal platform after proper modification [22-29]. The magnetic nanoparticles' application is quite common in recent literature due to its facile synthesis, APTES modification, and the high magnetic moment $[26,30,31]$. Though there are some advantages of encapsulated probes in the liposomal matrix for amplification of signals, from previous reports, it can be noted that the reliability of the detection remains questionable, especially in low concentration range $[26,31]$. Therefore, a successful combination of the liposomal matrix with magnetic nanoparticles can be applied to construct a new class of the biosensor where multiple detections can strengthen the results.

Energized by few recent reports on liposomal amplification and magnetic separation, in this study, a dual-functional signal amplification system containing fluorescent quantum dots (QDs) embedded and methylene blue-encapsulated liposomes (QDsliposome@MB) has been synthesized for the detection of Chikungunya virus E1 protein (CHIK-VP). Recombinant CHIK-VP has been taken here as an example to establish the sensing methodology. This new class of nanocomposite, containing fluorescent and an electrochemical sensing probe, can provide double responsive sensing of a single analyte to enhance the system's reliability over other liposome-based platforms. In addition to different concentrations of CHIK-VP, the specific antibody-conjugated QDs-liposome@MB and $\mathrm{Fe}_{3} \mathrm{O}_{4}$ nanoparticles can bind with the CHIK-VP, and it can make a sandwich structure, as pictured in Scheme 1. The whole conjugates (QDsliposome@MB with CHIK-VP-Fe ${ }_{3} \mathrm{O}_{4}$ ) have been separated magnetically from the medium to discard the interferences and excess liposomes. A surfactant can then disrupt the liposomal formation and release the fluorophores and redox probes for analysis. Hence, several probes can come out from the conjugates in the presence of a few numbers of CHIK-VP, and the detection signal can be amplified in both processes of fluorescence and electrochemical differential pulse voltammetry (DPV), respectively. In combination with the magnetic separation and dual-mode detection, here, it can be expected to establish a new sensing mechanism where dual signals from a single analyte make more reliable testing results for real sample analysis.

\section{Materials and methods}

\section{Chemicals and biological materials}

Dry toluene, 1-octadecene, cadmium oxide (CdO), selenium (Se), hexadecylamine (HAD), trioctylphosphine oxide (TOPO), trioctylphosphine (TOP), (3-aminopropyl)triethoxysilane (APTES), $N$-hydroxy succinimide (NHS), $N$-(3-(dimethylamino)-propyl)- $N$ '-ethylcarbodiimide hydrochloride (EDC), and methylene blue were purchased from Sigma-Aldrich (St Louis, MO, USA). 1-Palmitoyl-2-oleoylsn-glycero-3-phosphocholine (DOPC), 1,2-distearoyl-snglycero-3-phosphoethanolamine- $N$-[amino(polyethylene glycol)-2000] (ammonium salt) (DSPE-PEG 2000 amine), and 1,2dioleoyl-sn-glycero-3-phospho-(1'-rac-glycerol) (DOPG) were acquired from Avanti polar lipids (Alabaster, AL, USA). 28\% (w/v) ammonia solution is obtained from Duksan Pure Chemical Co., Ltd. (Ansan-si, South Korea). Phosphatebuffered saline (PBS), $\mathrm{FeCl}_{2} \cdot 4 \mathrm{H}_{2} \mathrm{O}, \mathrm{FeCl}_{3} \cdot 6 \mathrm{H}_{2} \mathrm{O}$, methanol, chloroform, acetone, and sodium citrate were purchased from Wako Pure Chemical Industries Ltd. (Japan).

Recombinant Chikungunya virus E1 protein [ab 187240] and anti-Chikungunya virus antibody [B 1413M] [ab 130889] were purchased from Abcam Inc. (Cambridge, UK). For conducting selectivity test, white-spot syndrome virus (WSSV), hepatitis E virus-like particles (HEV-LP), Zika virus, and influenza virus A (H3N2) were kindly provided by Dr. Jun Satoh, National Research Institute of Aquaculture of Japan Fisheries Research and Education Agency, Dr. Tian-Cheng Li of National Institute of Infectious Diseases, Japan, Professor K. Morita of Institute of Tropical Medicine Nagasaki University, and Dr. C. Kawakami of the Yokohama City Institute of Health (Yokohama Japan), respectively.

\section{Apparatus}

Dynamic light scattering (DLS) measurements were performed using a Zetasizer Nano series (Malvern Inst. Ltd., 


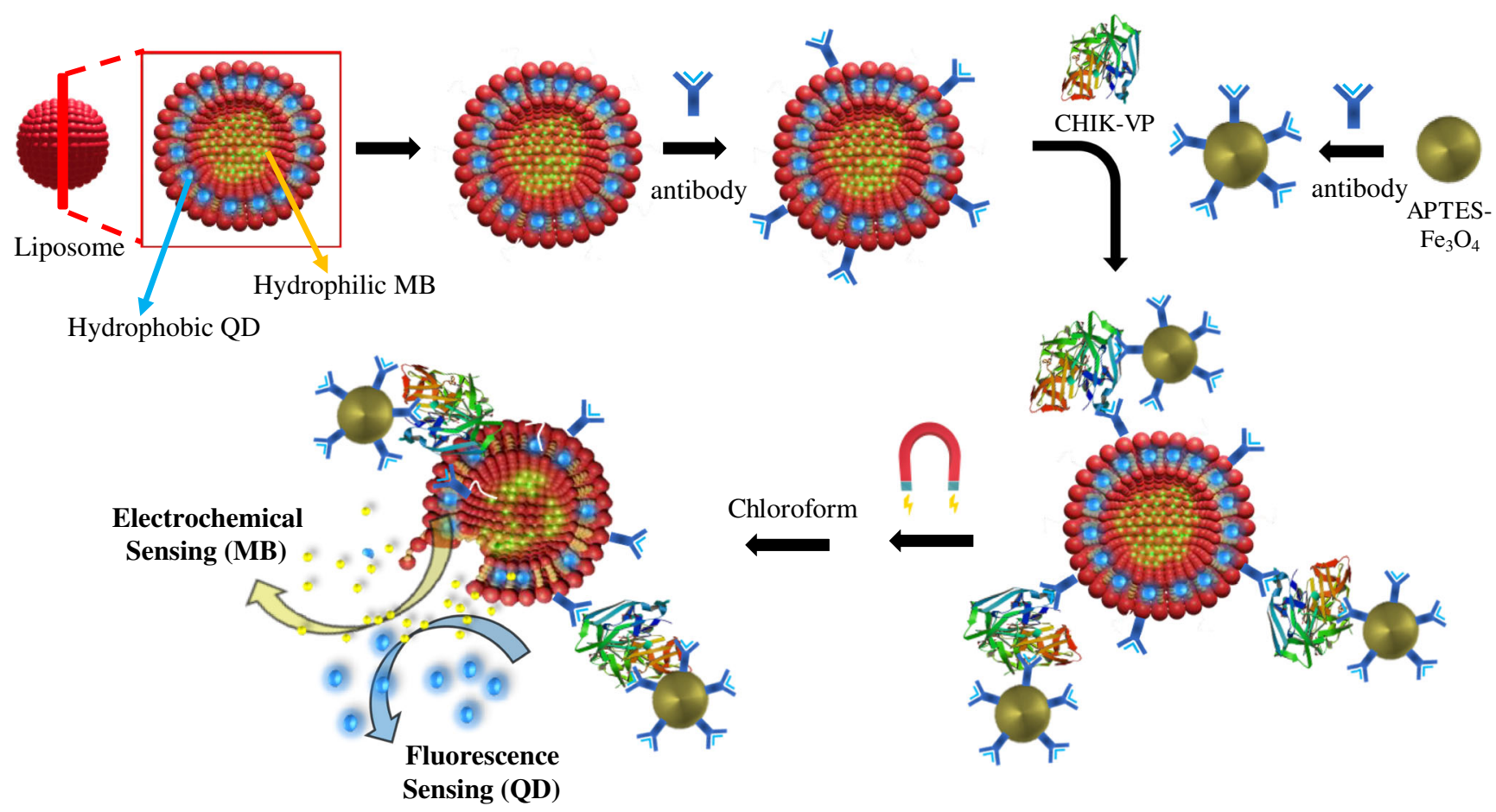

Scheme 1 Schematic representation of the formation of QDs-liposome@ MB and its sandwich hybridization with $\mathrm{Fe}_{3} \mathrm{O}_{4}$ nanoparticles and its dual-mode detection mechanism for CHIK-VP detection

Malvern, UK). A confocal laser scanning microscope (FV1000, Olympus, Tokyo, Japan) was used to take the liposome image using a stage thermocontrol system (Thermoplate, Tokai Hit, Shizuoka, Japan). Fluorescence spectra and UVvis absorption was taken by using a microplate reader (Infinite F500; TECAN, Ltd., Männedorf, Switzerland). Transmission electron microscopy (TEM) images of QDs, $\mathrm{Fe}_{3} \mathrm{O}_{4}$, liposomes, and their nanocomposites were obtained by JEOL TEM (JEOL, Tokyo, Japan). Electrochemical DPV was performed by an SP-150 (BioLogic.inc, Tokyo, Japan) in a saturated $\mathrm{Ag} / \mathrm{AgCl}$, with a conventional three-electrode cell consisting of a glassy carbon disk electrode (4 $\mathrm{mm}$ in diameter) as the counter, reference, and working electrodes, respectively (EC frontier, Tokyo, Japan).

\section{Preparation of CdSe QDs}

Necessary precursors such as CdO, ODE, HDA, TOP, Se, and OA were used to perform the organometallic hot-injection synthesis of hydrophobic CdSe QDs followed by a previously reported procedure [32].

\section{Synthesis of APTES-coated $\mathrm{Fe}_{3} \mathrm{O}_{4}$ nanoparticles}

The synthesis of magnetic $\mathrm{Fe}_{3} \mathrm{O}_{4}$ nanoparticle was followed by a previously reported standard method [33, 34]. Assynthesized magnetic $\mathrm{Fe}_{3} \mathrm{O}_{4}$ nanoparticles were coated with APTES by previously reported salinization method. To dissolve the APTES, dry toluene was used as the reaction medium, and finally, the as-synthesized $\mathrm{Fe}_{3} \mathrm{O}_{4}$ nanoparticles were added into the solution. To obtain the APTES-coated $\mathrm{Fe}_{3} \mathrm{O}_{4}$ nanoparticles, the mixture of the solution was refluxed at $120{ }^{\circ} \mathrm{C}$ for $20 \mathrm{~h}$ with continuous stirring. Finally, the APTES-coated $\mathrm{Fe}_{3} \mathrm{O}_{4}$ nanoparticles were rinsed with fresh toluene to remove the remaining APTES and were dried overnight and stored.

\section{Preparation of CdSe QD-embedded and methylene blue-encapsulated liposome}

The as-synthesized hydrophobic CdSe QDs were centrifuged for $10 \mathrm{~min}$ at $11,000 \times \mathrm{g}$ and then re-dispersed in chloroform to measure the concentration. Methylene blue (MB) solutions were prepared by dilution method from its stock solution of $10 \mathrm{mM}$ in PBS.

Twenty microliters of hydrophobic CdSe QDs dissolved in chloroform and $200 \mu \mathrm{L}$ of $10 \mathrm{mM}$ phospholipid mixtures solution of DOPC: DOPG: DSPE-PEG 2000 (molar ratio 50:40:10) in chloroform were added into 5 - $\mathrm{mL}$ glass vials and was evaporated by a flow of nitrogen gas to produce a thin homogeneous lipid film layer on the glass wall [22]. Then, the vial was stored in a vacuum desiccator for $12 \mathrm{~h}$ to evaporate completely. The fluorescence image of lipid film containing QDs is given in Fig. S1, ESM. To make the homogeneous lipid suspension, $1 \mathrm{~mL}$ of the MB solution (various concentrations as mentioned later) was used to 
hydrate the lipid film and agitated on a vortex mixer until the lipid film was entirely detached from the glass walls. The process of forming the liposome has been schematically presented in Fig. S2. Finally, the lipid suspension was dialyzed using a 2-kDa dialysis bag for $24 \mathrm{~h}$ to get purified unilamellar monodisperse QDs-liposome@MB by membrane filtering method.

\section{Antibody conjugation on QDs-liposome@MB and $\mathrm{Fe}_{3} \mathrm{O}_{4}$ nanoparticles}

The anti-CHIK-VP antibody was conjugated to the aminefunctionalized liposome and APTES-coated $\mathrm{Fe}_{3} \mathrm{O}_{4}$ nanoparticles separately, according to the previously reported protocols [35-37]. Initially, the carboxyl group of antibodies was activated using EDC/NHS. After that, the as-synthesized QDsliposome@MB and APTES-coated $\mathrm{Fe}_{3} \mathrm{O}_{4}$ were added to conjugate the antibody separately and incubated for $1 \mathrm{~h}$ at room temperature. The amine group of DSPE-PEG ${ }_{2000}$ phospholipids in the liposome and the APTES of $\mathrm{Fe}_{3} \mathrm{O}_{4}$ nanoparticles conjugate with the activated carboxylic group of antibodies, and the solution was purified by centrifugation for $10 \mathrm{~min}$ at $10,000 \mathrm{rpm}$ to remove the unreacted antibodies and the other coupling agents. The method of sensor preparation and its detection has been schematically presented in Fig. S2 in the ESM.

\section{Optical and electrochemical sensing of CHIK-VP}

Antibody-conjugated QDs-liposome@ $\mathrm{MB}$ and $\mathrm{Fe}_{3} \mathrm{O}_{4}$ nanoparticles were added with various CHIK-VP concentrations, as mentioned later, and incubated for $10 \mathrm{~min}$ to make the sandwich structure. After the antibody-virus binding, an external magnet of $10 \mathrm{mT}$ was placed at the bottom of the mixture solution to remove the detection solutions' impurities and excess reactants. After separating, the detection solution was re-dispersed in a fresh PBS buffer ( $\mathrm{pH}$ 6.8) and transferred in a 96-well microplate. For the disruption of the liposome, $0.1 \mathrm{mM}$ of $5 \mu \mathrm{L}$ chloroform was added in the solution, as mentioned in earlier reports [14], which triggered the liposome's disruption, releasing embedded QDs and encapsulated MB from the liposome. The solution was excited at $400 \mathrm{~nm}$, and the fluorescence intensity was measured in a range of $630-750 \mathrm{~nm}$ before and after the addition of chloroform. Similarly, the solution was separately mixed with the PBS electrolyte. Electrochemical DPV was performed by an SP-150 (BioLogic.inc, Tokyo, Japan) in a conventional three-electrode cell consisting of a glassy carbon disk electrode ( $4 \mathrm{~mm}$ in diameter) as working, a Pt wire as counter and a saturated $\mathrm{Ag} / \mathrm{AgCl}$, electrode as a reference electrode (EC frontier, Tokyo, Japan) at a fix scan window of -0.4 to $0.0 \mathrm{~V}$.

\section{Results and discussions}

\section{Characterizations of QDs-liposome@MB and $\mathrm{Fe}_{3} \mathrm{O}_{4}$ nanoparticles}

To make the precise size of the liposome, the specific composition of phospholipids of DOPC, DOPG, and DSPE-PEG ${ }_{2000}$ amine (50:30:20) were taken according to our previous reports [22]. As-synthesized, hydrophobic CdSe QDs were used to get embedded in the lipid bilayer of liposome during the film formation step of the lipid. MB was also incorporated while following the hydration step of the liposome so that MB can reside in the inner core of the liposome. After that, $0.2 \mu \mathrm{m}$ of the polycarbonate membrane was used as a filter to remove the excess MB from the liposome solution. Simultaneously, $\mathrm{Fe}_{3} \mathrm{O}_{4}$ nanoparticles were synthesized by the sol-gel method, and APTES was coated on it through the standard process of salinization. Initially, these three nanoparticles (QDs, $\mathrm{Fe}_{3} \mathrm{O}_{4}$, and liposome) were characterized by TEM, as shown in Fig. 1. In Fig. 1a, QDs are presented as uniformly dispersed with the range of 5-7 nm in size, where the particle distribution shows in Fig. 1b. The UV-absorption peak at $650 \mathrm{~nm}$ and the fluorescence spectra at $670 \mathrm{~nm}$ of the QDs indicate the successful preparation of the CdSe (Fig. 1c) [38]. The QDs are dark red under UV light, as shown in Fig. 1d. The liposomes are shown in homogeneously distributed spherical form, as presented in the TEM image of Fig. 1e. The liposome structures are also characterized by the confocal images where the differential interference contrast (DIC) image (Fig. 1f) and fluorescent image (Fig. 1g) of liposome displays the completely spherical formation while emitting the strong red fluorescence of QDs in the lipid bilayer. The TEM image of the $\mathrm{Fe}_{3} \mathrm{O}_{4}$ nanoparticles is shown in Fig. 1h. The average diameter of $26.5 \mathrm{~nm}$ is in a range of 22-34 nm of size, as presented in the bar diagram of Fig. 1i. Hydrodynamic radii of $\mathrm{Fe}_{3} \mathrm{O}_{4}$ nanoparticles, QDsliposome@MB, and QDs-liposome@MB $\|\mathrm{CHIK}-\mathrm{VP}\| \mathrm{Fe}_{3} \mathrm{O}_{4}$ sandwich hybridization nanoconjugates are shown in Fig. $1 \mathrm{j}$. The average size of the as-prepared $\mathrm{Fe}_{3} \mathrm{O}_{4}$ and QDsliposome@MB are found as 15 and $200 \mathrm{~nm}$, respectively, which resembles the size from their corresponding TEM images. However, after the QDs-liposome@MB||CHIK$\mathrm{VP} \| \mathrm{Fe}_{3} \mathrm{O}_{4}$ sandwich nanoconjugates was formed, the size of the nanoconjugates structure increases near to $900 \mathrm{~nm}$, which indicates the successful construction of the sandwich hybridized structure.

\section{Formation of QDs-liposome@MB and its optimized condition for virus detection}

The as-synthesized QDs-liposome@MB has been initially investigated for the suitable surfactant to release embedded fluorescent molecules. Among the different surfactants commonly used for the disruption of liposomal formation [39], 

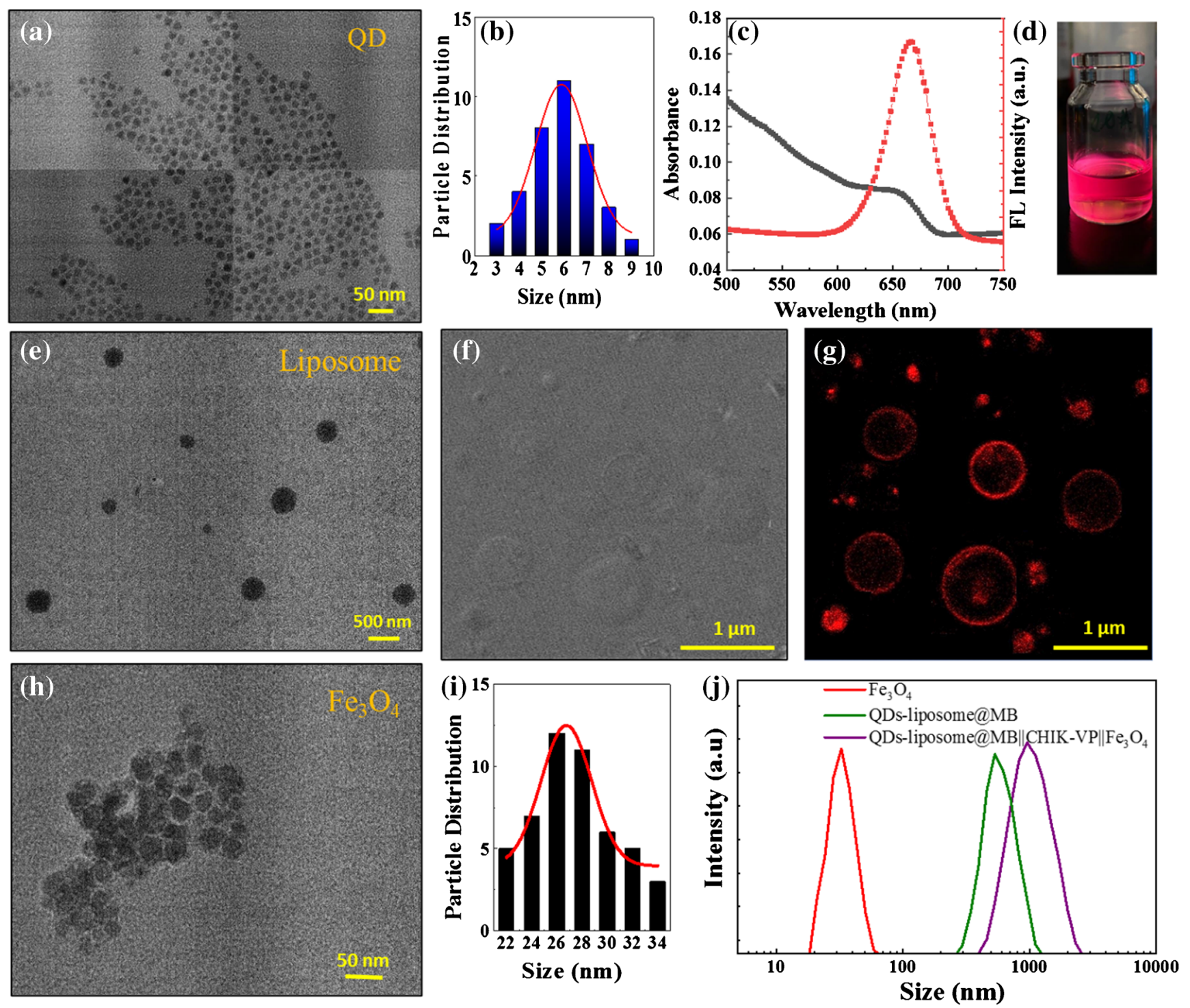

Fig. 1 Characterizations of the as-synthesized CdSe QDs, $\mathrm{Fe}_{3} \mathrm{O}_{4}$ nanoparticles, and QDs-liposome@MB. a TEM images, b particle size distribution, $\mathbf{c}$ UV-Vis absorption and fluorescence emission spectra, and $\mathbf{d}$ fluorescence image under UV light of CdSe QDs. e TEM images and $\mathbf{f}, \mathbf{g}$

chloroform shows the best result compared to Triton $\mathrm{X}$ and Tween 20 (Fig. 2a) [40, 41]. In the case of a 1:1 mixture of chloroform and methanol, the liposome's initial perturbation is slightly higher than only chloroform. However, after some time of incubation, the release has been noticed highest in chloroform. As the dissolution of the lipid layer in the chloroform is a slow process, the optimized time for the complete release has been chosen as $10 \mathrm{~min}$, as shown in Fig. 2b. After that, the fluorescence enhancement has reached its saturation, confirming the liposome's dissolution time is $10 \mathrm{~min}$. The amount of CdSe QDs has also been optimized with the fixed amount of liposome of $10^{3}$ particles $\mathrm{mL}^{-1}$. Three different concentrations of QDs have been taken to check the optimum condition where the QDs can be entirely embedded in the confocal images of QDs-liposome@MB. h TEM image and i particle distribution of $\mathrm{Fe}_{3} \mathrm{O}_{4}$ nanoparticles, (j) hydrodynamic radius of $\mathrm{Fe}_{3} \mathrm{O}_{4}$ nanoparticles, QDs-liposome@MB, and QDs-liposome@MB||CHIK$\mathrm{VP} \| \mathrm{Fe}_{3} \mathrm{O}_{4}$ sandwich nanoconjugates

liposome's hydrophobic surface. In the case of 0.5 and $1 \mathrm{mg} \mathrm{mL} \mathrm{m}^{-1}$ QD concentration, the fluorescence enhancement is quite satisfactory compared to the low level of $0.1 \mathrm{mg} \mathrm{mL}^{-1}$. However, in the case of $1 \mathrm{mg} \mathrm{mL}^{-1}$, the QDs are not only embedded in the surface but also penetrated inside the liposome, as shown in the inset of Fig. 2c. Due to the hydrophobic nature of the QDs, the encapsulated amount of the QDs inside the liposome is completely random and thus should be avoided. Therefore, the moderate concentration of $0.5 \mathrm{mg} \mathrm{mL}^{-1}$ of CdSe QDs has been selected for further liposome formation. A similar phenomenon is also observed in the case of DSPE lipid concentration. This amine groupcontaining lipid has been used in this work to produce the amine functionalization on the surface of the liposome, where 

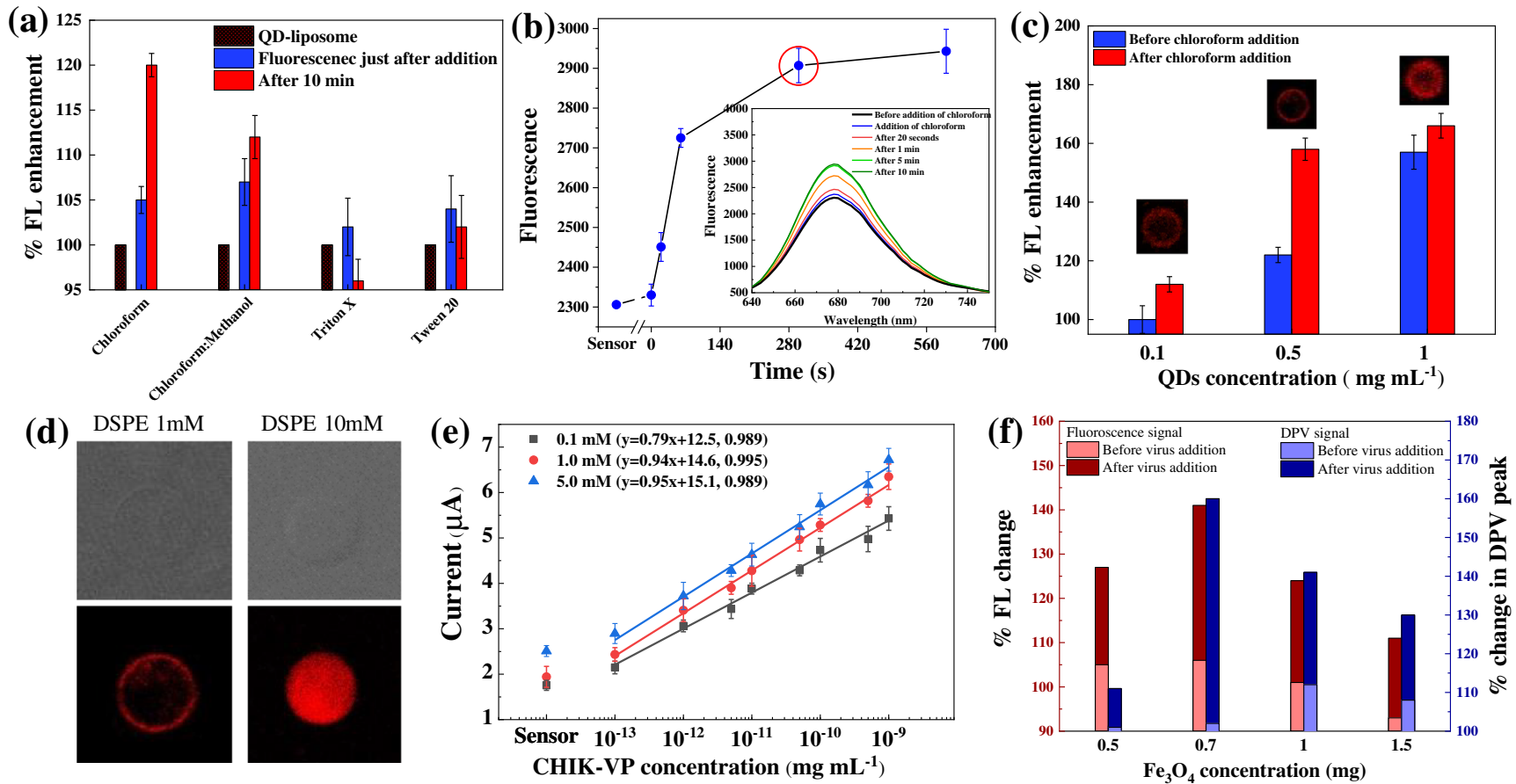

Fig. 2 a Effect of different surfactants on the disruption of the QDsliposome@MB, b time-dependent study on the disruption of the QDsliposome@MB, c optimization of the concentration of embedded CdSe QDs in the formation of QDs-liposome@MB, $\mathbf{d}$ confocal images of the QDs-liposome@MB with different concentration of amine-

functionalized DSPE lipid, e optimization of the encapsulated MB, and f optimization of the concentration of $\mathrm{Fe}_{3} \mathrm{O}_{4}$ nanoparticles for the conjugation of the QDs-liposome@ $\mathrm{MB}\|\mathrm{CHIK}-\mathrm{VP}\| \mathrm{Fe}_{3} \mathrm{O}_{4}$ nanoconjugates in CHIK-VP sensing

the antibody can bind through its carboxylic group [42]. Therefore, it is always good to take the maximum amount of DSPE lipid in the lipid mixture composition without hampering the structure to load the maximum number of antibodies. However, a higher concentration than $1 \mathrm{mM}$ can spill the QDs inside the core. Therefore, to avoid the QD encapsulation, less than $1 \mathrm{mM}$ of the DSPE lipid has been used (Fig. 2d).

In the electrochemical sensing, the concentration of the encapsulated redox probe is the most crucial parameter. The maximum concentration of MB can enhance sensitivity. However, the possibility of leakage or the background signal increases with the increasing concentration, resulting in reduced reliability [43]. Therefore, the encapsulation of MB concentration in the liposome was optimized. During the liposome synthesis, three levels of MB concentration $(0.1,1$, and $5 \mathrm{mM})$ were used for the MB encapsulation in the core of the liposome and measured different concentrations of CHIK-VP. It is evident from Fig. 2e; all different concentrations of MB display excellent linearity in the DPV signal. However, the sensor's blank value in the case of $5 \mathrm{mM}$ concentration is very high, indicating the possible leakage of the MB. Therefore, the highest concentration of $5 \mathrm{mM} \mathrm{MB}$ has been rejected. Compared with 0.1 and $1 \mathrm{mM}$, peak intensities of $1 \mathrm{mM} \mathrm{MB}$ are best suited according to their slope of the calibration lines, which is used for the remaining studies.

Additionally, after optimizing different liposome composition with the concentration of the embedded QDs and encapsulated
$\mathrm{MB}$, the construction of the QDs-liposome@MB $\mid \mathrm{CHIK}$ $\mathrm{VP} \| \mathrm{Fe}_{3} \mathrm{O}_{4}$ nanoconjugates were investigated with a different concentration ratio of the $\mathrm{Fe}_{3} \mathrm{O}_{4}$ nanoparticles and QDsliposome@MB. In this sensing work, the analyte of CHIK-VP bound with antibody-conjugated QDs-liposome@MB and $\mathrm{Fe}_{3} \mathrm{O}_{4}$ in a sandwich formation and then separated by applying a magnetic step. Therefore, it is obvious that the higher number of magnetic $\mathrm{Fe}_{3} \mathrm{O}_{4}$ nanoparticles can increase magnetic separation efficiency. However, an excess amount of $\mathrm{Fe}_{3} \mathrm{O}_{4}$ nanoparticles can bind on the virus surface itself rather than conjugate of the liposome, which may generate a false-negative signal. On the other side, the fewer amount of $\mathrm{Fe}_{3} \mathrm{O}_{4}$ may be unable to bind the virus as well as with the liposomes, producing false-positive signals. Therefore, using the amount of magnetic $\mathrm{Fe}_{3} \mathrm{O}_{4}$ nanoparticle should be optimized, which is also crucial in this work. A concentration range of $10^{-13}-10^{-8} \mathrm{~g} \mathrm{~mL}^{-1}$ of CHIK-VP has been applied to the different amounts of magnetic $\mathrm{Fe}_{3} \mathrm{O}_{4}$ nanoparticles with a fixed concentration of QDs-liposome@MB. As shown in Fig. 2f, the magnetically isolated QDs-liposome@MB $\|$ CHIK$\mathrm{VP} \| \mathrm{Fe}_{3} \mathrm{O}_{4}$ nanoconjugates have been tested both fluorometric and DPV method before and after the addition of chloroform. In the case of a low amount of $\mathrm{Fe}_{3} \mathrm{O}_{4}$, the magnetic nanoconjugates contain a lesser amount of virus particle than the $0.7 \mathrm{mg}$, which indicates the partial binding of viruses.

On the other hand, a high amount of $\mathrm{Fe}_{3} \mathrm{O}_{4}$ of 1 and $1.5 \mathrm{mg}$, though the magnetic adduct successfully separated the viruses. However, it self-quenched the signal due to the $\mathrm{MB}-\mathrm{Fe}_{3} \mathrm{O}_{4}$ 

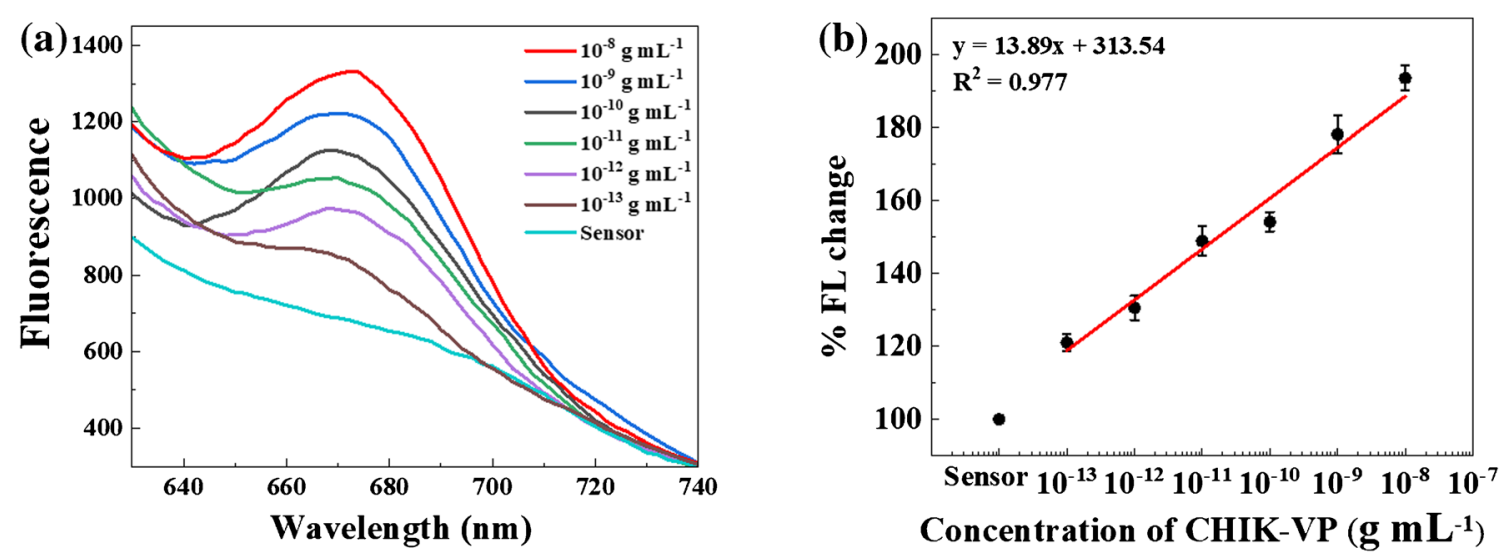

Concentration of CHIK-VP $\left(\mathrm{g} \mathrm{mL}^{-1}\right)$
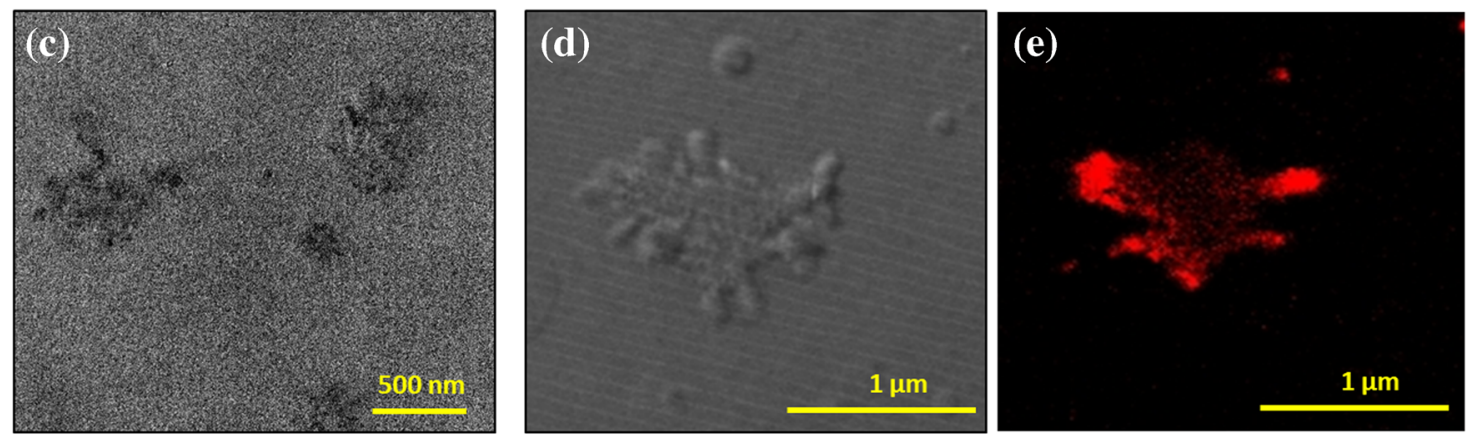

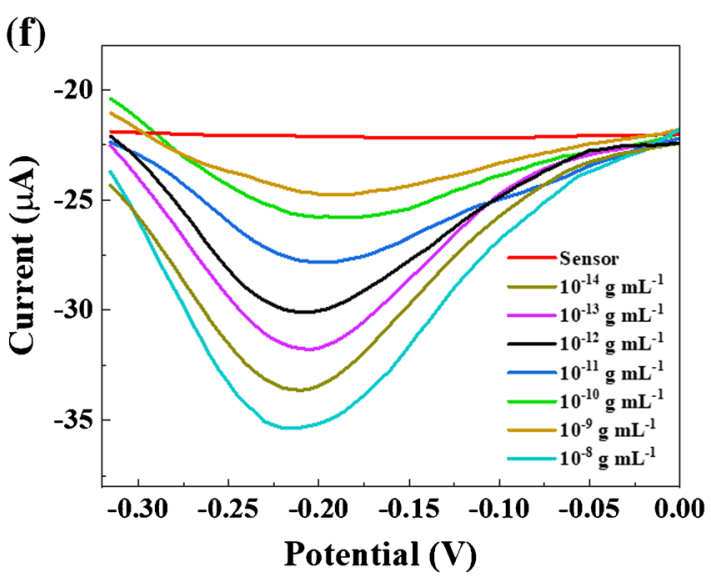

Fig. 3 Detection of CHIK-VP: a fluorescence enhancement of CdSe QDs after release from the embedded structure of QDs-liposome@MB $\mid \mathrm{CHIK}$ $\mathrm{VP} \| \mathrm{Fe}_{3} \mathrm{O}_{4}$ nanoconjugates, $\mathbf{b}$ calibration line in the concentration range of $10^{-13}-10^{-8} \mathrm{~g} \mathrm{~mL}^{-1}$ of CHIK-VP, c TEM image, d DIC, and $\mathbf{e}$ fluorescent confocal images of the QDs-liposome@MB\|CHIK-

and $\mathrm{QD} \mathrm{Fe}_{3} \mathrm{O}_{4}$ interactions. Therefore, optimizing all the results, $0.7 \mathrm{mg}$ of $\mathrm{Fe}_{3} \mathrm{O}_{4}$ nanoparticles proves to be the bestchosen concentration for using in this virus detection system.

\section{Detection of CHIK-VP by QDs-liposome@MB- $\mathrm{Fe}_{3} \mathrm{O}_{4}$ system}

After optimizing all the parameters, the QDs-liposome@MB$\mathrm{Fe}_{3} \mathrm{O}_{4}$ system was tested for the applicability for the detection of different concentrations of CHIK-VP. Before the addition

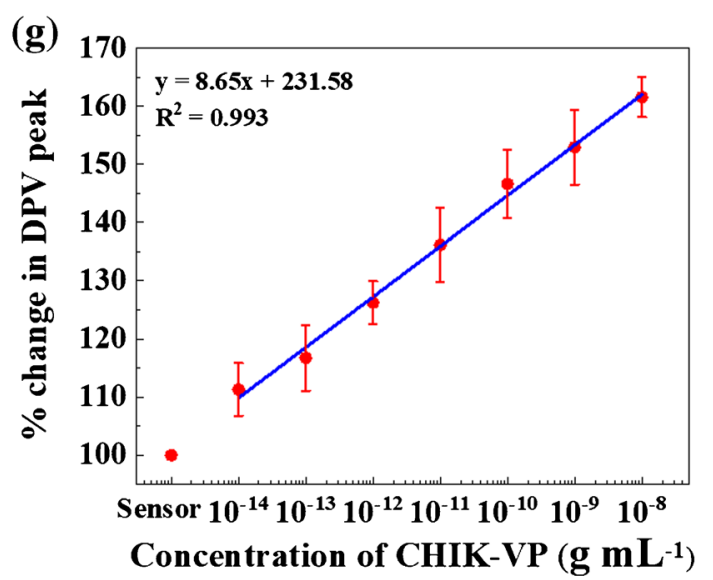

$\mathrm{VP}|| \mathrm{Fe}_{3} \mathrm{O}_{4}$ nanoconjugates after disruption by chloroform, $\mathbf{f}$ DPV peak of $\mathrm{MB}$ enhancement and its $\mathbf{g}$ calibration line, after release from the encapsulated structure of QDs-liposome@MB || $\mathrm{CHIK}-\mathrm{VP} \| \mathrm{Fe}_{3} \mathrm{O}_{4}$ nanoconjugates in the concentration range of $10^{-14}-10^{-8} \mathrm{~g} \mathrm{~mL}^{-1}$ of CHIK-VP

of CHIK-VP, there are free antibody-conjugated QDsliposome@MB and $\mathrm{Fe}_{3} \mathrm{O}_{4}$ in the reaction medium. However, there is no substantial interaction between these two composites. After adding different concentrations of CHIK-VP and incubating for $10 \mathrm{~min}$, the liposome and nanoparticles were bound with the virus through their corresponding specific antibodies conjugated on the surface of each to make the QDs-liposome@ $\mathrm{MB}\|\mathrm{CHIK}-\mathrm{VP}\| \mathrm{Fe}_{3} \mathrm{O}_{4}$ sandwich structure. The nanoconjugates were separated magnetically and used to measure the virus concentration by the 
Table 1 A comparison table for this current method with other virus detection methods in terms of materials, LOD, and detection range

\begin{tabular}{|c|c|c|c|c|c|}
\hline Detection method & Materials used & Analytes & LOD & Detection range & References \\
\hline Paper-based colorimetry & $\begin{array}{l}\text { Wax-patterned paper layer, } \\
\text { AuNP }\end{array}$ & $\mathrm{NoV}$ & $\begin{array}{c}9.5 \times 10^{4} \text { copies } \\
\mathrm{mL}^{-1}\end{array}$ & $\begin{array}{l}1.58 \times 10^{5}-7.9 \times 10^{7} \text { copies } \\
\mathrm{mL}^{-1}\end{array}$ & {$[45]$} \\
\hline Fluorometry & AuNP, CdSeTeS QDs & Influenza & $3 \times 10^{-10} \mathrm{~g} \mathrm{~mL}^{-1}$ & - & [46] \\
\hline Fluorometry & Colloidal GNP & Influenza & $1.39 \times 10^{-8} \mathrm{~g} \mathrm{~mL}^{-1}$ & $5-50 \times 10^{-9} \mathrm{~g} \mathrm{~mL}^{-1}$ & {$[47]$} \\
\hline Fluorometry & QDs, AuNPs & Influenza & $9 \times 10^{-7} \mathrm{~g} \mathrm{~mL}^{-1}$ & $0.27-12 \times 10^{-9} \mathrm{~g} \mathrm{~mL}^{-1}$ & {$[48]$} \\
\hline Immuno-chromatography & Colloidal gold & $\begin{array}{l}\text { CHIKV } \\
\text { (S27/African) }\end{array}$ & $\geq 1 \times 10^{5} \mathrm{PFU} \mathrm{mL}{ }^{-1}$ & $\begin{array}{l}2.9 \times 10^{-4}-1.6 \times 10^{-8} \mathrm{PFU} \\
\mathrm{mL}^{-1}\end{array}$ & [49] \\
\hline Electrochemical & ZnO NR, PDMS & Influenza & $1 \times 10^{-12} \mathrm{~g} \mathrm{~mL}^{-1}$ & $1-10 \times 10^{-9} \mathrm{~g} \mathrm{~mL}^{-1}$ & [49] \\
\hline Electrochemical & Graphene, AuNP & NoV-LP & $100 \mathrm{pM}$ & $100 \mathrm{pM}-3.5 \mathrm{nM}$ & {$[50]$} \\
\hline Electrochemical & $\begin{array}{l}\text { Carbon microarray electrode, } \\
\text { AuNP }\end{array}$ & MERS-CoV & $1 \times 10^{-12} \mathrm{~g} \mathrm{~mL}^{-1}$ & $0.01-10,000 \times 10^{-9} \mathrm{~g} \mathrm{~mL}^{-1}$ & {$[51]$} \\
\hline Electrochemical & Gold microelectrode & ZIKV protein & $10 \mathrm{pM}$ & $10 \mathrm{pM}-1 \mathrm{nM}$ & {$[52]$} \\
\hline $\begin{array}{l}\text { Fluorometry } \\
\text { Electrochemical }\end{array}$ & QDs-liposome@MB & CHIK-VP & $\begin{array}{l}0.56 \times 10^{-12} \mathrm{~g} \mathrm{~mL}^{-1} \\
32.7 \times 10^{-15} \mathrm{~g} \mathrm{~mL}^{-1}\end{array}$ & $\begin{array}{l}10^{-13}-10^{-8} \mathrm{~g} \mathrm{~mL}^{-1} \\
10^{-14}-10^{-8} \mathrm{~g} \mathrm{~mL}^{-1}\end{array}$ & This work \\
\hline
\end{tabular}

fluorometric and DPV separately. The fluorometric study was carried out at $400 \mathrm{~nm}$ and $672 \mathrm{~nm}$ of wavelength for the excitation and emission, respectively, and has shown a strong signal of the QDs after disrupting the liposomes, triggered by chloroform. As shown in Fig. 3a, the fluorescence intensities of different CHIK-VP concentrations in the range of $10^{-13}$ $10^{-8} \mathrm{~g} \mathrm{~mL}^{-1}$ evidently indicates the existence of an increasing concentration of released QDs. Before the addition of viruses, the QDs are embedded inside the hydrophobic core of the liposomal wall. Due to the closely packed orientation, the fluorescence of the QDs is not showing any strong peak under excitation. However, after the disruption of the liposome, the free QDs can produce a signal in fluorescence. The calibration line (Fig. 3b), based on the intensity of fluorescence, conserves the linearity over the full range of concentration with a correlation coefficient of 0.977 . The limit of detection (LOD) has been calculated and obtained from the calibration line, which is $0.56 \mathrm{pg} \mathrm{mL}^{-1}$ derived from the $3 \sigma / \mathrm{s}$ method (three times the standard deviation of the lowest concentration of target/slope of the calibration line) [44]. The TEM (Fig. 3c) and confocal images (Fig. 3d and e) of the nanoconjugates after chloroform addition also corroborate with our hypothesis about the disruption structure of the liposomes.

Simultaneously, the QDs-liposome@MB\|CHIK$\mathrm{VP} \| \mathrm{Fe}_{3} \mathrm{O}_{4}$ nanoconjugates have also been tested in the electrochemical DPV for the measurement of the released MB. Based on the hypothesis, with the addition of chloroform in the liposome mixture, the released MB comes into the buffer. As shown in Fig. 3f, the DPV signal of MB at $-0.22 \mathrm{~V}$ represents CHIK-VP concentration in the concentration range of $10^{-14}-10^{-8} \mathrm{~g} \mathrm{~mL}^{-1}$. The calibration line accomplished from the peak current in DPV was calculated and plotted in Fig. $3 \mathrm{~g}$, which shows the linearity with the correlation coefficient of 0.993 . The LOD has been measured from the calibration line of $32.7 \mathrm{fg} \mathrm{mL}^{-1}$, calculated from the $3 \sigma / \mathrm{s}$ method [44] which is one order less than the optical detection due to the high sensitivity of the electrochemical process.

In comparison with other virus detection methods, as presented in Table 1, the LOD and the range of concentration have clear superiority over other virus detection methods. As CHIK's detection or its protein is rarely reported in the literature, we have compared our results with other methods. In the case of colorimetric and fluorometric sensing, which are the most common detection method due to its simplicity and the possibility for naked-eye detection, the LOD is too poor, not applicable for CHIK diagnosis of this disease. In electrochemical methods, a relatively low LOD has been reported. However, due to the dual approach, the combination of fluorescent and electrochemical methods, the LOD, and the wide range of concentration range of this current work is significantly better than the others.

\section{Selectivity of the sensor}

As the antibody conjugation controlled the sandwich structure formation between the target CHIK-VP with QDsliposome@MB and $\mathrm{Fe}_{3} \mathrm{O}_{4}$ nanoparticles, it is evident that the sensor should possess high specificity. To confirm its specificity, a selectivity test was performed with other viruses such as WSSV, Zika, influenza virus $\left(10^{5}\right.$ copies $\left.\mathrm{mL}^{-1}\right)$, and hepatitis E virus-like particle $\left(10^{-9} \mathrm{~g} \mathrm{~mL}^{-1}\right)$ and BSA as a negative control. The concentration of all interferences taken for selectivity is higher than their concentrations found in blood, serum, or other sources. The BSA does not show any significant signal in both the detection method of fluorometric and DPV (Fig. 4) as expected. Other interfering viruses do not significantly change the signal because the sensing method includes magnetic separation of impurities. A minimal fluorometric response has been observed, which may occur due to 


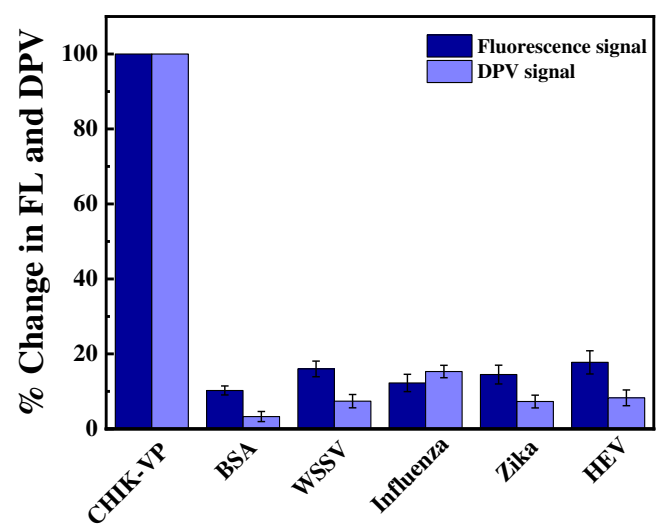

Fig. 4 Selectivity test: fluorometric and DPV signal enhancement of QDs-liposome@MB in the presence of the target CHIK-VP $\left(10^{5}\right.$ copies $\left.\mathrm{mL}^{-1}\right)$, BSA matrix, $10^{5}$ copies $\mathrm{mL}^{-1}$ of WSSV, Zika and influenza virus and hepatitis $\mathrm{E}$ virus-like particles $\left(10^{-9} \mathrm{~g} \mathrm{~mL}^{-1}\right)$

the nonspecific interaction with the liposome membrane, which is significantly low compared to the target CHIKVP's signal. Therefore, from this selective study, it can be noted that the fluorescence and the DPV signal originates only if the specific target virus is present, which confirms its practical applicability for the virus detection purpose. However, for its real sample analysis, the stability of these materials is a major concern. Due to the formation of the liposomal platform, there is a possibility of leakage of the liposome structure's encapsulated materials over time. In Fig. S3 of ESM, the materials' stability shows acceptable results within 2 weeks of its preparation, a disadvantage for its practical analysis. However, the liposomal structure can be replaced by any other stable nanocarrier like solid-lipid nanoparticles or metalorganic frameworks to enhance the stability for the real sample analysis in the future.

\section{Conclusion}

In this work, a liposome-based dual-functional signal amplification system with the combination of magnetic $\mathrm{Fe}_{3} \mathrm{O}_{4}$ nanoparticles has been developed to detect CHIK-VP. For the successful blending of these two components, few numbers of virus particles have been able to produce amplified intense signals even in presence of other interferences. A hydrophobic red fluorescent $\mathrm{CdSe}$ QDs embedded and $\mathrm{MB}$ solution encapsulated liposome with APTES-coated $\mathrm{Fe}_{3} \mathrm{O}_{4}$ nanoparticles were prepared separately and conjugated to the anti-CHIKVP antibody to make specific binding for the target virus. In presence of various CHIK-VP concentrations, the QDsliposome@MB and magnetic $\mathrm{Fe}_{3} \mathrm{O}_{4}$ nanoparticles formed the sandwich-like structured complex which was disrupted for the virus detection purpose. The LOD has been found as $0.56 \mathrm{pg} \mathrm{mL}^{-1}$ and $32.7 \mathrm{fg} \mathrm{mL}^{-1}$ in fluorometric and DPV process, respectively. Due to the successful fabrication of dual-mode detection probes in a single system, the liposomal matrix could be applied for double responsive sensing for a single analyte. This enhances the reliability of the results exceptionally well, signifying the proposed platform's superiority over other liposome-based systems. Also, the negligible cross-reactivity with other viruses and different matrices, along with low background signals, confirm the specific behavior of the sensor, indicating its potential application in different virus sensing approaches in the near future.

Supplementary Information The online version contains supplementary material available at https://doi.org/10.1007/s00604-020-04656-2.

Acknowledgments The authors thank Professor K. Morita of Institute of Tropical Medicine Nagasaki University, Dr. C. Kawakami of the Yokohama City Institute of Health (Yokohama Japan), Dr. Jun Satoh of National Research Institute of Aquaculture of Japan Fisheries Research and Education Agency, and Dr. Tian-Cheng Li of Department of Virology, National Institute of Infectious Diseases for providing Zika virus, influenza virus A (H3N2), WSSV, and HEV-LP, respectively, for the selectivity test.

Funding ABG (No. 19F19064) and OJA (No. 19F19348) received support from the Japan Society for the Promotion of Science (JSPS) (postdoctoral fellowship) and the Heiwa Nakajima Foundation.

\section{Compliance with ethical standards}

Conflict of interest The authors declare that they have no competing interests.

\section{References}

1. Shojaei TR, Tabatabaei M, Shawky S, Salleh MAM, Bald D (2015) A review on emerging diagnostic assay for viral detection: the case of avian influenza virus. Mol Biol Rep 42(1):187-199

2. Luo S-C, Sivashanmugan K, Liao J-D, Yao C-K, Peng H-C (2014) Nanofabricated SERS-active substrates for single-molecule to virus detection in vitro: a review. Biosen Bioelectrons 61:232-240

3. Vollmer F, Yang L (2012) Review label-free detection with high-Q microcavities: a review of biosensing mechanisms for integrated devices. Nanophotonics 1(3-4):267-291

4. Chowdhury AD, Park EY (2019) Detection of infectious viruses using advanced nanobiotechnology for green society. Green Science and Technology:316-331

5. Achadu OJ, Kagawa K, Kawahito S, Park EY (2020) Fluoroimmunoassay of influenza virus using sulfur-doped graphitic carbon nitride quantum dots coupled with $\mathrm{Ag}_{2} \mathrm{~S}$ nanocrystals. Microchim Acta 187(8):466

6. Nguyen HH, Park J, Kang S, Kim M (2015) Surface plasmon resonance: a versatile technique for biosensor applications. Sensors 15(5):10481-10510

7. Kirsch J, Siltanen C, Zhou Q, Revzin A, Simonian A (2013) Biosensor technology: recent advances in threat agent detection and medicine. Chem Soc Rev 42(22):8733-8768

8. Khoris IM, Chowdhury AD, Li T-C, Suzuki T, Park EY (2020) Advancement of capture immunoassay for real-time monitoring of hepatitis E virus-infected monkey. Anal Chim Acta 1110:64-71

9. Ilkhani H, Hughes T, Li J, Zhong CJ, Hepel M (2016) Nanostructured SERS-electrochemical biosensors for testing of 
anticancer drug interactions with DNA. Biosen Bioelectrons 80: 257-264

10. Stobiecka M, Ratajczak K, Jakiela S (2019) Toward early cancer detection: focus on biosensing systems and biosensors for an antiapoptotic protein survivin and survivin mRNA. Biosen Bioelectrons 137:58-71

11. Incani RN, Ferrer E, Hoek D, Ramak R, Roelfsema J, MughiniGras L, Kortbeek T, Pinelli E (2017) Diagnosis of intestinal parasites in a rural community of Venezuela: advantages and disadvantages of using microscopy or RT-PCR. Acta Trop 167:64-70

12. Deng H, Gao Z (2015) Bioanalytical applications of isothermal nucleic acid amplification techniques. Anal Chim Acta 853:30-45

13. Haque F, Li J, Wu H-C, Liang X-J, Guo P (2013) Solid-state and biological nanopore for real-time sensing of single chemical and sequencing of DNA. Nano Today 8(1):56-74

14. Zhou J, Wang Q-x, Zhang C-y (2013) Liposome-quantum dot complexes enable multiplexed detection of attomolar DNAs without target amplification. J Am Chem Soc 135(6):2056-2059

15. Zhao W, Ali MM, Brook MA, Li Y (2008) Rolling circle amplification: applications in nanotechnology and biodetection with functional nucleic acids. Angew Chem Int Ed 47(34):6330-6337

16. Hu J, C-y Z (2010) Sensitive detection of nucleic acids with rolling circle amplification and surface-enhanced Raman scattering spectroscopy. Anal Chem 82(21):8991-8997

17. Ganganboina AB, Chowdhury AD, Khoris IM, Nasrin F, Takemura K, Hara T, Abe F, Suzuki T, Park EY (2020) Dual modality sensor using liposome-based signal amplification technique for ultrasensitive norovirus detection. Biosen Bioelectrons 157:112169

18. Chowdhury AD, Park EY (2019) Methylene blue-encapsulated liposomal biosensor for electrochemical detection of sphingomyelinase enzyme. Sensors Actuators B Chem 301:127153

19. Johari-Ahar M, Karami P, Ghanei M, Afkhami A, Bagheri H (2018) Development of a molecularly imprinted polymer tailored on disposable screen-printed electrodes for dual detection of EGFR and VEGF using nano-liposomal amplification strategy. Biosen Bioelectrons 107:26-33

20. Chang Y-F, Fu C, Chen Y-T, Jou AF-J, Chen C-C, Chou C, Ho JaA (2016) Use of liposomal amplifiers in total internal reflection fluorescence fiber-optic biosensors for protein detection. Biosen Bioelectrons 77:1201-1207

21. Das S, Saha P (2018) A review of some advanced sensors used for health diagnosis of civil engineering structures. Measurement 129: 68-90

22. Chowdhury AD, Sharmin S, Nasrin F, Yamazaki M, Abe F, Suzuki T, Park EY (2020) Use of target-specific liposome and magnetic nanoparticle conjugation for the amplified detection of norovirus. ACS Appl Bio Mater 3(6):3560-3568

23. Hsin T-M, Wu K, Chellappan G (2012) Magnetically immobilized nanoporous giant proteoliposomes as a platform for biosensing. Analyst 137(1):245-248

24. Harjanto D, Lee J, Kim J-M, Jaworski J (2013) Controlling and assessing the surface display of cell-binding domains on magnetite conjugated fluorescent liposomes. Langmuir 29(25):7949-7956

25. He Y, Li M, Jiang W, Yang W, Lin L, Xu L, Fu F (2016) Phosphatidylserine-functionalized $\mathrm{Fe}_{3} \mathrm{O}_{4} @ \mathrm{SiO}_{2}$ nanoparticles combined with enzyme-encapsulated liposomes for the visual detection of $\mathrm{Cu}^{2+}$. J Mater Chem B 4(4):752-759

26. Chowdhury AD, Ganganboina AB, Y-c T, H-c C, R-a D (2018) Multifunctional GQDs-Concanavalin $\mathrm{A} @ \mathrm{Fe}_{3} \mathrm{O}_{4}$ nanocomposites for cancer cells detection and targeted drug delivery. Anal Chim Acta 1027:109-120

27. Dutta Chowdhury A, Agnihotri N, R-a D, De A (2017) Label-free and nondestructive separation technique for isolation of targeted DNA from DNA-protein mixture using magnetic $\mathrm{Au}-\mathrm{Fe} 3 \mathrm{O} 4$ nanoprobes. Anal Chem 89(22):12244-12251
28. Ganganboina AB, Doong R-A (2019) Graphene quantum dots decorated gold-polyaniline nanowire for impedimetric detection of carcinoembryonic antigen. Sci Rep 9(1):7214

29. Pastucha M, Farka Z, Lacina K, Mikušová Z, Skládal P (2019) Magnetic nanoparticles for smart electrochemical immunoassays: a review on recent developments. Microchim Acta 186(5):312

30. Yang L, Li N, Wang K, Hai X, Liu J, Dang F (2018) A novel peptide $/ \mathrm{Fe}_{3} \mathrm{O}_{4} @ \mathrm{SiO}_{2}$-Au nanocomposite-based fluorescence biosensor for the highly selective and sensitive detection of prostatespecific antigen. Talanta 179:531-537

31. Babamiri B, Hallaj R, Salimi A (2018) Ultrasensitive electrochemiluminescence immunosensor for determination of hepatitis B virus surface antigen using CdTe@CdS-PAMAM dendrimer as luminescent labels and $\mathrm{Fe}_{3} \mathrm{O}_{4}$ nanoparticles as magnetic beads. Sensors Actuators B Chem 254:551-560

32. Nwaji N, Achadu OJ, Nyokong T (2018) Photo-induced resonance energy transfer and nonlinear optical response in ball-type phthalocyanine conjugated to semiconductor and graphene quantum dots. New J Chem 42(8):6040-6050

33. Ganganboina AB, Chowdhury AD, R-a D (2017) Nano assembly of $\mathrm{N}$-doped graphene quantum dots anchored $\mathrm{Fe}_{3} \mathrm{O}_{4} /$ halloysite nanotubes for high performance supercapacitor. Electrochim Acta 245:912-923

34. Yuan P, Southon PD, Liu Z, Green ME, Hook JM, Antill SJ, Kepert CJ (2008) Functionalization of halloysite clay nanotubes by grafting with $\gamma$-aminopropyltriethoxysilane. J Phys Chem C 112(40):15742-15751

35. Nasrin F, Chowdhury AD, Takemura K, Kozaki I, Honda H, Adegoke O, Park EY (2020) Fluorometric virus detection platform using quantum dots-gold nanocomposites optimizing the linker length variation. Anal Chim Acta 1109:148-157

36. Pei Z, Anderson H, Myrskog A, Dunér G, Ingemarsson B, Aastrup $\mathrm{T}$ (2010) Optimizing immobilization on two-dimensional carboxyl surface: $\mathrm{pH}$ dependence of antibody orientation and antigen binding capacity. Anal Biochem 398(2):161-168

37. Nasrin F, Chowdhury AD, Takemura K, Lee J, Adegoke O, Deo VK, Abe F, Suzuki T, Park EY (2018) Single-step detection of norovirus tuning localized surface plasmon resonance-induced optical signal between gold nanoparticles and quantum dots. Biosen Bioelectrons 122:16-24

38. Maestro LM, Rodríguez EM, Rodríguez FS, la Cruz MI-d, Juarranz A, Naccache R, Vetrone F, Jaque D, Capobianco JA, Solé JG (2010) CdSe quantum dots for two-photon fluorescence thermal imaging. Nano Lett 10(12):5109-5115

39. Singh S, Vardhan H, Kotla NG, Maddiboyina B, Sharma D, Webster TJ (2016) The role of surfactants in the formulation of elastic liposomal gels containing a synthetic opioid analgesic. Int J Nanomedicine 11:1475

40. Tasi L-M, Liu D-Z, Chen W-Y (2003) Microcalorimetric investigation of the interaction of polysorbate surfactants with unilamellar phosphatidylcholines liposomes. Colloids Surf A Physicochem Eng Asp 213(1):7-14

41. Tang Y, Tang D, Zhang J, Tang D (2018) Novel quartz crystal microbalance immunodetection of aflatoxin B1 coupling cargoencapsulated liposome with indicator-triggered displacement assay. Anal Chim Acta 1031:161-168

42. Vabbilisetty P, Sun X-L (2014) Liposome surface functionalization based on different anchoring lipids via Staudinger ligation. Org Biomol Chem 12(8):1237-1244

43. Chen D, Wen S, Peng R, Gong Q, Fei J, Fu Z, Weng C, Liu M (2019) A triple signal amplification method for chemiluminescent detection of the cancer marker microRNA-21. Microchim Acta 186(7):410

44. Dutta Chowdhury A, R-a D (2016) Highly sensitive and selective detection of nanomolar ferric ions using dopamine functionalized 
graphene quantum dots. ACS Appl Mater Interfaces 8(32):2100221010

45. Han KN, Choi J-S, Kwon J (2016) Three-dimensional paper-based slip device for one-step point-of-care testing. Sci Rep 6(1):25710

46. Takemura K, Adegoke O, Takahashi N, Kato T, Li T-C, Kitamoto N, Tanaka T, Suzuki T, Park EY (2017) Versatility of a localized surface plasmon resonance-based gold nanoparticle-alloyed quantum dot nanobiosensor for immunofluorescence detection of viruses. Biosen Bioelectrons 89:998-1005

47. Chang Y-F, Wang S-F, Huang JC, Su L-C, Yao L, Li Y-C, Wu S-C, Chen Y-MA, Hsieh J-P, Chou C (2010) Detection of swine-origin influenza $A(H 1 N 1)$ viruses using a localized surface plasmon coupled fluorescence fiber-optic biosensor. Biosen Bioelectrons 26(3):1068-1073

48. Li X, Lu D, Sheng Z, Chen K, Guo X, Jin M, Han H (2012) A fast and sensitive immunoassay of avian influenza virus based on labelfree quantum dot probe and lateral flow test strip. Talanta 100:1-6
49. Okabayashi T, Sasaki T, Masrinoul P, Chantawat N, Yoksan S, Nitatpattana N, Chusri S, Vargas REM, Grandadam M, Brey PT (2015) Detection of chikungunya virus antigen by a novel rapid immunochromatographic test. J Clin Microbiol 53(2):382-388

50. Chand R, Neethirajan S (2017) Microfluidic platform integrated with graphene-gold nano-composite aptasensor for one-step detection of norovirus. Biosen Bioelectrons 98:47-53

51. Layqah LA, Eissa S (2019) An electrochemical immunosensor for the corona virus associated with the Middle East respiratory syndrome using an array of gold nanoparticle-modified carbon electrodes. Microchim Acta 186(4):224

52. Kaushik A, Yndart A, Kumar S, Jayant RD, Vashist A, Brown AN, Li C-Z, Nair M (2018) A sensitive electrochemical immunosensor for label-free detection of Zika-virus protein. Sci Rep 8(1):9700

Publisher's note Springer Nature remains neutral with regard to jurisdictional claims in published maps and institutional affiliations. 